\title{
Effect of isobaric breathing gas shifts from air to heliox mixtures on resolution of air bubbles in lipid and aqueous tissues of recompressed rats
}

\author{
O. Hyldegaard $\cdot$ D. Kerem $\cdot$ Y. Melamed
}

Received: 1 October 2010/Accepted: 24 January 2011/Published online: 12 February 2011

(C) The Author(s) 2011. This article is published with open access at Springerlink.com

\begin{abstract}
Deep tissue isobaric counterdiffusion that may cause unwanted bubble formation or transient bubble growth has been referred to in theoretical models and demonstrated by intravascular gas formation in animals, when changing inert breathing gas from nitrogen to helium after hyperbaric air breathing. We visually followed the in vivo resolution of extravascular air bubbles injected at $101 \mathrm{kPa}$ into nitrogen supersaturated rat tissues: adipose, spinal white matter, skeletal muscle or tail tendon. Bubbles were observed during isobaric breathing-gas shifts from air to normoxic $(80: 20)$ heliox mixture while at $285 \mathrm{kPa}$ or following immediate recompression to either 285 or $405 \mathrm{kPa}$, breathing 80:20 and 50:50 heliox mixtures. During the isobaric shifts, some bubbles in adipose tissue grew marginally for 10-30 min, subsequently they shrank and disappeared at a rate similar to or faster than during air breathing. No such bubble growth was observed in spinal white matter, skeletal muscle or tendon. In spinal white matter, an immediate breathing gas shift after the hyperbaric air exposure from air to both (80:20) and (50:50)
\end{abstract}

Communicated by Susan A. Ward.

O. Hyldegaard $(\square)$

Laboratory of Hyperbaric Medicine, Department of Anesthesia, Centre of Head-and-Orthopedics, Rigshospitalet,

University Hospital of Copenhagen, Blegdamsvej 9,

2100 Copenhagen $\varnothing$, Denmark

e-mail: ole.hyldegaard@dadlnet.dk

\section{Kerem}

Institute of Maritime Studies, School of Marine Sciences,

University of Haifa, Haifa, Israel

Y. Melamed

Hyperbaric Medical Center, Rambam

and Elisha Hospitals, Haifa, Israel heliox, coincident with recompression to either 285 or $405 \mathrm{kPa}$, caused consistent shrinkage of all air bubbles, until they disappeared from view. Deep tissue isobaric counterdiffusion may cause some air bubbles to grow transiently in adipose tissue. The effect is marginal and of no clinical consequence. Bubble disappearance rate is faster with heliox breathing mixtures as compared to air. We see no reason for reservations in the use of heliox breathing during treatment of air-diving-induced decompression sickness.

Keywords Gas exchange - Decompression sickness · Counterdiffusion $\cdot$ Helium $\cdot$ Nitrogen

\section{Introduction}

Super-saturation and formation of a gas phase induced by deep tissue isobaric counterdiffusion has been referred to in theoretical models and experimentally demonstrated by intravascular gas formation in animal models, when changing breathing gas from air to heliox (helium and oxygen mixture) in animals compressed to saturation on air (D'Aoust et al. 1977; Lambertsen and Idicula 1975). Such a counterdiffusion phenomenon could in theory also cause growth of existing nitrogen-containing bubbles and thus deterioration of symptoms of air-diving-induced decompression sickness (DCS). This has caused some reluctance to administer heliox mixtures to air divers presenting with DCS (Moon and Sheffield 1995), although DCS treatment regimes based on such mixtures have proven successful (Aharon-Peretz et al. 1993; Barnard and Elliott 1966; Bennett et al. 2007; Douglas and Robinson 1988; Drewry and Gormann 1993; Gorman 1996; Imbert 1996; Kol and Melamed 1993; Shupak et al. 1997). In addition, rats 
exposed to helium-induced DCS will deteriorate with consistent bubble growth during subsequent air breathing (Hyldegaard and Jensen 2007).

In previous reports in the experimental rat model, it was observed that decompression-induced nitrogen $\left(\mathrm{N}_{2}\right)$ bubbles in adipose tissue, will shrink consistently when the breathing gas is changed from air to heliox (80:20, i.e. $20 \%$ oxygen in $80 \%$ helium) (Hyldegaard and Madsen 1989) at normobaric (sea-level) conditions. This behavior was also seen when micro air bubbles are injected into the white substance of the spinal cord (Hyldegaard et al. 1991) as well as in aqueous tissues such as skeletal muscle or tendon (Hyldegaard and Madsen 1994) of decompressed rats. Further, we have shown that when the breathing gas switch from air to heliox (both 80:20 and 50:50) is followed by recompression bubbles will consistently shrink and disappear faster than during breathing of air, in both lipid and aqueous tissues (Hyldegaard et al. 2001).

In the case of perfusion-limited gas exchange, our previous observations can be explained by the lower solubility of helium in blood and tissues when compared with that of $\mathrm{N}_{2}$ (Langø et al. 1996; Weathersby and Homer 1980). In the case of diffusion limitation, the permeability (i.e. the product of the diffusion coefficient and tissue solubility coefficient) of helium in lipid tissues is smaller than that of $\mathrm{N}_{2}$. Counter current mechanisms may also be at work in some tissues, slowing down tissue helium uptake to a greater degree than the concomitant reduction in $\mathrm{N}_{2}$ desaturation (Homer et al. 1990; Sejrsen 1985; Sejrsen and Tønnesen 1972).

However, helium and $\mathrm{N}_{2}$ will not only exchange between blood and bubble but also with the surrounding tissue. In lipid tissues, the tissue-blood partition coefficient ratio for nitrogen is 2.6 times that of helium, which makes these tissues saturate (and desaturate) with helium more than twice as fast as with $\mathrm{N}_{2}$ (Hyldegaard and Madsen 1989; Langø et al. 1996; Weathersby and Homer 1980). Thus, a transient state of super-saturation may be created, that might cause growth of $\mathrm{N}_{2}$ bubbles during breathing of a heliox mixture as suggested by Lambertsen and Idicula (1975) and D'Aoust et al. (1977).

Two opposing bubble-oriented gas fluxes occur upon recompression combined with an air-heliox shift: $\mathrm{N}_{2}$ diffuses out into the tissue once hydrostatic pressure establishes reversed bubble-tissue gradients and helium diffuses into the bubble upon being washed into the tissue surrounding the bubble. Obviously, the higher the $\mathrm{N}_{2}$ tension gradient driving the first flux, the less chance for the second one to dominate and cause bubble growth. In previous experiments (Hyldegaard et al. 1991, 2001; Hyldegaard and Madsen 1989, 1994), the inert breathing gas switch from $\mathrm{N}_{2}$ to helium, and/or the recompression were done with a certain time delay after the hyperbaric air exposure.
Disregarding the fact that air bubbles within this time were observed to grow during breathing of air, indicating the existence of continued $\mathrm{N}_{2}$ super-saturation in the tissue, it could still be argued that a sufficiently large amount of $\mathrm{N}_{2}$ had been eliminated, that the bubble-tissue $\mathrm{PN}_{2}$ gradient following recompression was unduly high and that the influx of helium into the bubble caused by the subsequent faster rate of helium tissue saturation was not sufficient to make it grow or that a very modest growth went undetected in these experiments. Based on this reasoning, and in an effort to dispel any remnant concerns about the use of heliox in the treatment of air-DCS, we applied a modification of the previous experimental rat model, where extravascular injected micro air bubbles are studied by direct visualization during isobaric breathing gas shifts at $284 \mathrm{kPa}$ from air to heliox (80:20) in lipid and aqueous tissues. In addition, the combined effect of an immediate breathing gas shift from air to either heliox $(80: 20)$ or heliox (50:50) (i.e. the Comex $\mathrm{CX}_{30}$ treatment table; James et al. 1986) with recompression to 285 [heliox (80:20) experiments] or $405 \mathrm{kPa}$ [heliox (50:50) experiments] on micro air bubbles injected into spinal white matter subsequently exposed to $\mathrm{N}_{2}$ supersaturation, was also studied.

\section{Methods}

\section{General}

Female Wistar rats weighing 250-350 g were anesthetized with sodium thiomebumal $(0.1 \mathrm{~g} / \mathrm{kg})$ intraperitoneally and buprenorphine $0.01 \mathrm{mg} / \mathrm{kg}$ subcutaneously (Hedenqvist and Hellebrekers 2003) providing sufficient time for a nonparalyzed surgical- and sleep anesthetic depth during the experimental procedures in spontaneously breathing female rats (Roughan et al. 1999; Torbati et al. 1999; Zambricki and D'Alecy 2004). Depth of surgical anesthesia was maintained such that the hind paw withdrawal and tail pinch reflex were absent. If present, top-up of thiomebumal $0.01 \mathrm{~g} / \mathrm{kg}$ was supplied.

The rat was placed supine on the operating table, and a cannula was inserted into the trachea (i.e., polyethylene tubing, $1.5 \mathrm{~mm}$ ID). A catheter was placed in the left carotid artery for blood pressure registration. It was kept patent by continuous infusion of saline $(1 \mathrm{ml} / \mathrm{h})$ (SAGE Instruments, syringe pump model 341). Mean arterial blood pressure (MAP) was measured using a Statham AA pressure and body temperature was measured using a thermocouple (Yellowstone) placed in the vagina. A continuous record was obtained on a Gould 2600 multichannel recorder. In some of the experiments, a thermo probe was placed superficially on the tissue to measure the temperature at the surface of the exposed tissue. In 
all experiments, the chamber temperature was regulated at $28-29^{\circ} \mathrm{C}$ to maintain a body temperature of $37^{\circ} \mathrm{C}$, as controlled by the vaginal thermometer. After bubble disappearance and decompression from the second pressure exposure in both $\mathrm{A}$ and $\mathrm{B}$ experiments, the thorax and abdomen were opened for further microscopic examination for intra- or extravascular gas formation, whereupon the rat was killed by exsanguinations while still anesthetized.

\section{Compression and decompression procedures}

All experimental groups of rats were subjected to a maximum of two pressure exposures; the first compression was breathing hyperbaric air to induce a state of tissue $\mathrm{N}_{2}$ super saturation (Fig. 1). In experiments on adipose tissue, the initial exposure was $4 \mathrm{~h}$ at $314 \mathrm{kPa}$ followed by a 20-min decompression in three stages (Hyldegaard and Madsen 1995; Hyldegaard et al. 1991). In experiments on spinal white matter, muscle, and tendon the initial hyperbaric exposure was $1 \mathrm{~h}$ at $355 \mathrm{kPa}$ followed by a 7.5-min decompression with short pauses at 324 and $152 \mathrm{kPa}$ (Hyldegaard et al. 2001; Hyldegaard and Madsen 1994). In A experiments (Fig. 1), bubble injection commenced after the first pressure exposure and rats were subsequently compressed to $285 \mathrm{kPa}$ during which isobaric breathing gas shifts from air to heliox $(80: 20)$ breathing were performed. In B experiments (Fig. 1), bubble injection was done before the first pressure exposure, thus allowing for an immediate breathing gas shift upon surfacing from the first exposure with a subsequent recompression to either 285 or $405 \mathrm{kPa}$ (Fig. 1).

Animal preparation and experimental protocol

Experiments were divided into either group A or group B experiments. The experimental protocol for $\mathrm{A}$ and $\mathrm{B}$ experiments are shown in Fig. 1.

\section{Group A}

After decompression from the initial hyperbaric exposure, the rats were placed under a heating lamp and allowed to breathe air at $101.3 \mathrm{kPa}$. From 1 (spinal white matter) or 1-3 (all other tissues) air bubbles were injected with a micropipette into the specified tissue (adipose 1.5-2.0 $\mathrm{l}$, spinal white matter and muscle $1.0-1.5 \mu \mathrm{l}$ or tendon $0.5-1.0 \mu \mathrm{l}$ ), according to the designated experimental sub-group (Table 1 for number of animals in each subgroup). In adipose tissue and skeletal muscle tissue injected bubbles were covered with gasimpermeable Mylar and bubbles in spinal white matter and tendon covered with gas impermeable glass.
Exposed tissues were also covered with a polyethylene membrane to prevent evaporation. The micro bubble injection technique and surgical procedures has been described in previous reports (Hyldegaard and Madsen 1994, 1995; Hyldegaard et al. 1991). The duration of the bubble injection interval was 30-75 min, depending on the tissue studied. During this period, a heating lamp maintained body temperature at $37^{\circ} \mathrm{C}$ as controlled by the vaginal thermometer. The rat was replaced in the chamber, the lid was resealed, and the microscope was focused on a bubble for determination of the prerecompression bubble size. Subsequently, with the rat still breathing air, the pressure chamber was recompressed at $101.3 \mathrm{kPa} \times \min ^{-1}$ to a maximum of $285 \mathrm{kPa}$. The second bubble-size measurement, mainly reflecting bulk compression, was then obtained. In order to ensure, that a sufficient amount of $\mathrm{N}_{2}$ (in mol) had accumulated in the tissues after recompression, the air breathing interval at the second pressure exposure was chosen based on a $\mathrm{N}_{2}$ tissue half-time in female Wistar rat abdominal adipose tissue of approximately $29 \mathrm{~min}$, since the tissue perfusion is $0.105 \mathrm{ml}$ blood $\times$ $\mathrm{g}^{-1} \times \min ^{-1}$ (Madsen et al. 1975) and the partition coefficient $(\lambda)$ for $\mathrm{N}_{2}$ between $85 \%$ lipid and blood is $0.066 / 0.0148$ (Weathersby and Homer 1980). After some 40-55 min (and with one exception of 22-30 min in adipose tissue) breathing air at $285 \mathrm{kPa}$, an isobaric breathing gas shift from air to heliox (80:20) was performed. While at pressure, the bubbles were monitored continuously until their total disappearance, at which time immediate decompression at $101.3 \mathrm{kPa} \times \min ^{-1}$ was commenced, with continuous inspection for reappearance of the bubble.

\section{Group B}

After rat anesthesia and surgical preparations as described above, a micro air bubble of 1.0-1.5 $\mu \mathrm{l}$ was then injected into the posterior funiculus of the spinal cord, the position being similar to that of the A experiments (Hyldegaard et al. 1991). In order to allow for an immediate breathing gas shift to a heliox mixture followed by prompt recompression from the first hyperbaric air breathing exposure introducing the $\mathrm{N}_{2}$ supersaturation, bubble injection had to be done before the first pressure exposure (Fig. 1). Accordingly, after bubble injection, the rat was placed in the pressure chamber, the connections made and the chamber compressed to $355 \mathrm{kPa}$ with the rat breathing air (Fig. 1). Before decompression from the first pressure exposure began, the microscope was focused on the injected micro air bubble and the video recorder started for determination of the pre-decompression bubble size. During the 


\section{A-Experimental protocol.}

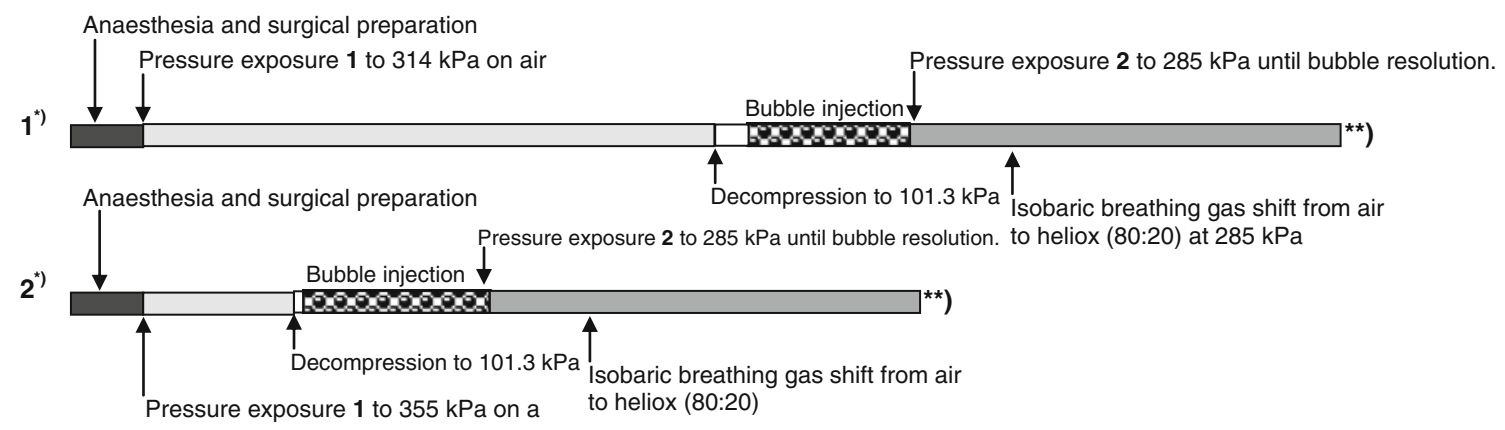

B-Experimental protocol.

Anaesthesia and surgical preparation Pressure exposure 2 to 285 or $405 \mathrm{kPa}$ breathing

| heliox (80:20) or (50:50) until bubble resolution.

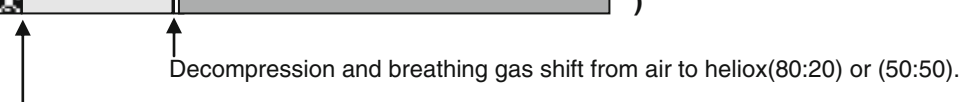

Pressure exposure 1 to $355 \mathrm{kPa}$ on air

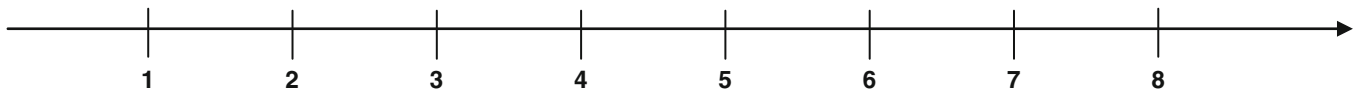

Time scale - hours

Fig. 1 Experimental protocol for A and B experiments. Horizontal bars represents time spent at the different experimental procedures. *1-2 Isobaric breathing gas shifts at $285 \mathrm{kPa} .1$ experimental protocol adipose tissue. 2 experimental protocol spinal white matter, skeletal muscle and tendon. **Termination times in each experiment depend on time of bubble resolution. Once bubbles disappeared from view, rats were decompressed and killed by means of exsanguinations

Table 1 Bubble shrinking rates-isobaric breathing gas shift from Air to Heliox (80:20) at $285 \mathrm{kPa}$

\begin{tabular}{|c|c|c|c|c|}
\hline \multirow[t]{2}{*}{ Tissue } & \multicolumn{2}{|c|}{$\begin{array}{l}\text { Bubble shrinking rate } \\
\mu \mathrm{m}^{2} \times 10^{-3} \times \mathrm{min}^{-1} \text { given } \pm \mathrm{SD}\end{array}$} & \multirow{2}{*}{\multicolumn{2}{|c|}{$\begin{array}{l}\text { Significance testing } \\
\text { Independent Student's } t \text { test }\end{array}$}} \\
\hline & $\operatorname{Air}^{\mathrm{a}}$ & Heliox $(80: 20)$ & & \\
\hline Adipose tissue & $\begin{array}{l}10.0 \pm 4.8 \\
N=6\end{array}$ & $\begin{array}{l}14.7 \pm 7.1 \\
N=4\end{array}$ & Air vs. He (80:20) & $P=0.20 \mathrm{NS}$ \\
\hline Spinal white matter & $\begin{array}{l}3.6 \pm 1.2 \\
N=9\end{array}$ & $\begin{array}{l}8.5 \pm 6.0 \\
N=5\end{array}$ & Air vs. He (80:20) & $P=0.03^{* *} \mathrm{~S}$ \\
\hline Skeletal muscle & $\begin{array}{l}5.3 \pm 1.2 \\
N=4\end{array}$ & $\begin{array}{l}9.8 \pm 1.2 \\
N=4\end{array}$ & Air vs. He $(80: 20)$ & $P=0.002^{* * *}$ \\
\hline Tendon & $\begin{array}{l}8.4 \pm 1.9 \\
N=5\end{array}$ & $\begin{array}{l}6.9 \pm 2.7 \\
N=4\end{array}$ & Air vs. He (80:20) & $P=0.34 \mathrm{NS}$ \\
\hline
\end{tabular}

$N$ number of rats, $N S$ not significant, $S$ significant

** The bubble shrinking rate during heliox (80:20) breathing was significantly faster than during air breathing in spinal white matter

*** The bubble shrinking rate during heliox (80:20) was significantly faster than during air breathing in skeletal muscle

${ }^{a}$ Data of air-breathing rats obtained from Hyldegaard et al. (2001)

7.5 min decompression phase, the bubble was continuously monitored. Once at $101.3 \mathrm{kPa}$, the breathing gas was immediately switched from air to heliox (80:20) or (50:50) and the pressure chamber was promptly recompressed: to $285 \mathrm{kPa}$ in the case of heliox $(80: 20)$ and to $405 \mathrm{kPa}$ in the case of heliox (50:50) [i.e. similar to the
Comex $_{30}$ heliox (50:50) treatment table, James et al. 1986). The bubbles were continuously monitored during the second recompression phase as well as at pressure, until they disappeared from view, followed by immediate decompression to $101.3 \mathrm{kPa}$ with continuous inspection for reappearance of the bubble as in group A. 
Pressurization system

Compression and decompression were performed in a specially designed vertical pressure chamber with a horizontal viewing port in the lid (Fig. 1 in Hyldegaard et al. 2001). The rat was strapped supine on a circular plate that could be lifted out of the chamber and serve as an operating platform. The plate had a mounting for a stereo-tactic headholding device, which was used in the spinal cord experiments (group B) in which the rat was in the prone position. When inside the chamber, the plate was positioned so the tissue under observation was placed $2 \mathrm{~cm}$ below the glass window in the chamber lid. The chamber was compressed on air through an inlet fitted with a regulator (AR 425, Baccara ${ }^{\mathrm{TM}}$ ) that maintained the desired chamber pressure. The chamber had penetrations for a copper spiral waterheating coil, infusion pump, pressure transducer, temperature sensors, and electric cables, as well as breathing gas supply and exhaust. The breathing mixture passed a T-connection for the rat's tracheal tube before escaping to the outside via a modified Ultralite mask (Orthomed ${ }^{\mathrm{TM}}$ ) overboard dump valve. The valve was adjusted to maintain a $2 \mathrm{cmH}_{2} \mathrm{O}$ positive breathing pressure inside the loop. The breathing gas flow was 1,500-2,000 ml/min (STPD), as verified by a Krohn ${ }^{\mathrm{TM}}$ 90044D flow meter attached to the outlet port outside the chamber.

\section{Bubble monitoring system}

Bubbles were observed through the chamber window at $\times 40$ magnification by means of a Wild ${ }^{\mathrm{TM}}$ M10 stereomicroscope with a long focal-length objective. Two flexible fiber optic light guides attached to a Volpo Intralux ${ }^{\mathrm{TM}} 5000$ lamp illuminated the bubble field. A Kappa $\mathrm{CF}^{\mathrm{TM}} 15 / 2$ color video camera was fitted to the microscope, and the field was both displayed on a TV screen and recorded on VHS videotape (Fig. 1 in Hyldegaard et al. 2001). With a frame-grabber board, real-time images could be grabbed and exported to a Macintosh ${ }^{\mathrm{TM}}$ computer. The bubble's apparent cross-sectional area on the microscopic image could be computed at any time by hand tracing its circumference (often irregular) and applying an IMAGE version 1.61 automated planimetry program (Rasband 1996). The computer program was calibrated by placing a metal rod, $200 \mu \mathrm{m}$ in diameter, on top of the exposed tissue and within the field of view.

Data analysis and statistics

Graphs depicting the evolution with time of apparent bubble cross-sectional area, from pre-compression, through compression and gas shifts, until the total dissolution of the bubble were first inspected visually for deflection points, trend reversals, obvious changes in slope, etc. Bubble analysis (see below) was performed in a random order, unblinded to the observer. Thereafter, for experiments in both groups, the mean bubble shrinking rate while breathing heliox mixing was calculated as the apparent cross-sectional area in $\mu \mathrm{m}^{2} \mathrm{~min}^{-1}$, assuming constant or near-constant slopes from the time of isobaric breathing gas shift (A experiments) or immediately post-compression (B experiments) until disappearance of bubble. When several bubbles were studied in one rat, their average shrinking rate was used in the statistical comparison. Mean values of bubble shrinking rates are given \pm SD.

\section{Group A experiment}

Test for normal distribution of data was done using the method of Kolmogorov and Smirnov. As appropriate, twoway ANOVA (Altman 1991) was performed in order to test whether the two independent variables, i.e. tissue (adipose tissue, spinal white matter, skeletal muscle or tendon) or breathing gas [air or heliox (80:20)] had any effect on the dependent variable, bubble shrinking rate, either independently or by the interaction of both. Further, unpaired Student's $t$ test was used to test the differences between mean bubble shrinking rates within each of the tissue subgroups in this experiment [heliox $(80: 20)$ breathing] to those of air-breathing rats from our previous report (Hyldegaard et al. 2001), exposed to exactly the same experimental conditions.

\section{Group B experiments}

To examine whether the difference between two mean values of calculated bubble shrinking rates, were different from zero, test for normality by means of Kolmogorov and Smirnov (KS) test followed by one-way ANOVA was performed on the difference between mean values in the different treatment groups (Altman 1991).

Data were analyzed using either the SPSS software (SPSS Inc. 1998) or GraphPad Instat ${ }^{\mathrm{TM}}$ version 3.06 for Windows $^{\mathrm{TM}}$, GraphPad ${ }^{\mathrm{TM}}$ Software (GraphPad 2003) and GraphPad Prism $^{\mathrm{TM}}$ version 5.03 for Windows ${ }^{\mathrm{TM}}$, Graph$\mathrm{Pad}^{\mathrm{TM}}$ Software (GraphPad 2009). For all comparisons, $P<0.05$ is regarded the limit for significance.

\section{Results}

General condition of animals

During experimental procedures, rats remained anesthetized and stable with respect to breathing and MAP (see below). Spontaneous rat movements were not observed in 
any of the experiments at any time point. During the initial pressure exposure in group A (non-operated) rats, MAP was between 120 and $150 \mathrm{mmHg}$ (range 110-170 $\mathrm{mmHg}$ ). In group B experiments, MAP was between 130 and $150 \mathrm{mmHg}$ (range 110-175). During decompression, it fell to a level of $100-120 \mathrm{mmHg}$ (range $80-150 \mathrm{mmHg}$ ) in both group A and B experiments. When the rats were recompressed breathing air, heliox (80:20 or 50:50), MAP varied over a wide range $120-150 \mathrm{mmHg}$ (range 110-180 mmHg) for both group A and B experiments.

In all experiments, vaginal temperature varied between 36.0 and $38.0^{\circ} \mathrm{C}$. Tissue temperatures were in the range $35.0-38.0^{\circ} \mathrm{C}$, and in most cases $36.0-37.0^{\circ} \mathrm{C}$, with a tendency toward a lower temperature in the tail tendon (35.0-37.0 $\left.{ }^{\circ} \mathrm{C}\right)$.

One rat died of DCS with innumerable bubbles in the veins after the long pressure exposure (i.e., $4 \mathrm{~h}$ ). In the surviving animals, no intra- or extravascular bubbles were observed during the microscopic examination performed after decompression from the second pressure exposure in both group A and B experiments.

State of tissue during observations

Group A experiments-isobaric gas shift at $285 \mathrm{kPa}$ $(N=$ number of rats $)$

Adipose tissue $(N=4)$ In all experiments, blood perfusion was clearly visible during the observation period. In two experiments, extravascular bubbles in the adipose tissue were observed following the first decompression, which disappeared from view during the second pressure exposure.

Spinal white matter $(N=5)$ In one rat, intravascular bubbles were observed traversing the pial vessels during the preparation phase after the initial pressure exposure. During the entire observation period, circulation in the larger pial vessels was clearly visible, whereas perfusion in the smaller vessels close to the injected bubble was impeded.

Skeletal muscle $(N=4)$ During the experiments, blood perfusion was clearly visible in vessels with a diameter of 10-15 $\mu \mathrm{m}$ and seemed unaffected throughout the experiment. Occasionally, small muscle fiber twitches could be seen.

Tendon $(N=4) \quad$ At all times, blood perfusion was clearly visible in the small vessels (10-15 $\mu \mathrm{m}$ diameter). When splitting the tail skin from the tendon, some bleeding was observed from the exposed skin.

At all times, blood perfusion was clearly visible in the small vessels (10-15 $\mu \mathrm{m}$ diameter). When splitting the tail skin from the tendon, some bleeding was observed from the exposed skin.

\section{Group B experiment: immediate recompression}

After bubble injection and subsequent compression to $355 \mathrm{kPa}$, the injected air bubble shrank slowly during breathing of air (not recorded). During the decompression phase while still breathing air from the first pressure exposure, injected micro air bubbles in both heliox $(80: 20)$ breathing $(N=6)$ and heliox (50:50) breathing $(N=5)$ experiments initially grew according to the simultaneous pressure reduction. Circulation in the larger pial vessels was clearly visible throughout all experiments, whereas perfusion in the smaller vessels close to the injected bubble became impeded during the decompression phase from the first pressure exposure. The subsequent recompression to $405 \mathrm{kPa}$ using heliox (50:50) breathing restored circulation in the vessels close to the bubble.

Comparability of experimental groups

The treatment groups in A experiments were not statistically different (by one-way ANOVA test) with respect to mean time from decompression to time of first observation and recompression. With respect to the mean size of injected bubbles in group B experiments they were not different when compared to air-breathing rats from our previous report (Hyldegaard et al. 2001).

Bubble dynamics in the different treatment groups

\section{Group A experiments}

Adipose tissue During the initial air breathing period, bubbles $(N=7)$ shrank consistently. When, after 40-50 min of air breathing, the breathing mixture was changed to heliox (80:20), two out of seven bubbles grew marginally while the rest showed a transient slowing of their shrinking rate. These transient behaviors lasted up to $30 \mathrm{~min}$ and subsequently all bubbles shrank until they disappeared from view. There was a tendency for larger bubbles to grow transiently whereas smaller bubbles did not. The mean \pm SD bubble shrinking rate during heliox $(80: 20)$ breathing was $(14.7 \pm 7.1) \times$ $10^{3} \mu \mathrm{m}^{2} \times \min ^{-1}$ (Fig. 2).

Spinal white matter During the initial air breathing period bubbles shrank slowly. After the breathing gas shift from air to heliox (80:20) all bubbles $(N=5)$ shrank consistently. No bubbles were observed to grow or reduce their rate of shrinking once heliox $(80: 20)$ breathing was initiated. The mean \pm SD bubble shrinking rate during heliox $(80: 20)$ breathing was $(8.5 \pm 6.0) \times 10^{3} \mu \mathrm{m}^{2} \times \min ^{-1}$ (Fig. 2). 


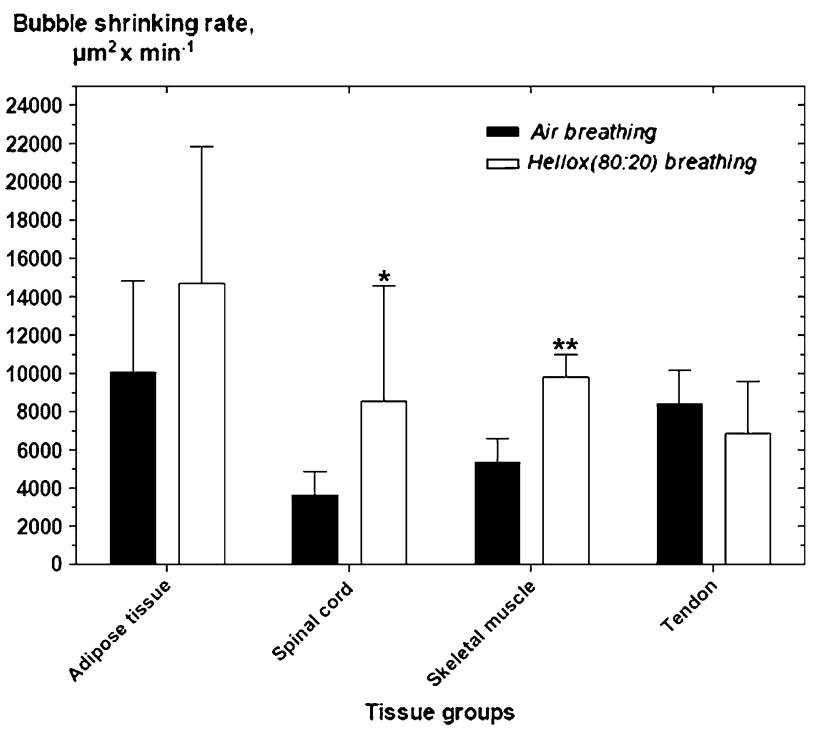

Fig. 2 Bars represent different bubble shrinking rates in $\mu \mathrm{m}^{2} \times \min ^{-1}( \pm \mathrm{SD})$, during either continuous air breathing at $285 \mathrm{kPa}$ (black bars with data from Hyldegaard et al. (2001) or after an isobaric breathing gas shift to normoxic heliox (80:20) at $285 \mathrm{kPa}$ (white bars), in adipose tissue, spinal white matter, skeletal muscle, and tendon in the rat. *Shrinking rates significantly different at the $P=0.03$ level. **Shrinking rates significantly different at the $P=0.002$ level (Table 1$)$

Skeletal muscle Bubble $(N=12)$ behavior post an preshift was the same as described above for spinal white matter. The mean \pm SD bubble shrinking rate during heliox (80:20) breathing was $(9.8 \pm 1.2) \times 10^{3} \mu \mathrm{m}^{2} \times \min ^{-1}$ (Fig. 2).

Tendon During air breathing bubbles shrank consistently. After heliox (80:20) breathing was started, all bubbles $(N=9)$ continued shrinking until they disappeared from view. Two bubbles were observed to slow down their rate of shrinkage for a period of 7-10 min, from which point on they continued shrinking at the pre-shift rate until disappearing from view. The mean \pm SD bubble shrinking rate during heliox $(80: 20)$ breathing was $(6.9 \pm 2.7) \times 10^{3} \mu \mathrm{m}^{2} \times \min ^{-1}$ (Fig. 2).

\section{Group B experiments}

Heliox (80:20) Recompression breathing heliox (80:20) caused all bubbles to shrink consistently until they disappeared from view. No transient bubble growth or reduced rates of shrinkage were observed. The mean \pm SD bubble shrinking rate was $(10.2 \pm 5.1) \times 10^{3} \mu \mathrm{m}^{2} \times \min ^{-1}$ (Fig. 3).

Heliox (50:50) immediate breathing gas shift to heliox (50:50) and recompression to $405 \mathrm{kPa}$ cased all bubbles $(N=5)$ to likewise shrink consistently until they disappeared from view. The mean \pm SD bubble shrinking rate was $(23.3 \pm 2.2) \times 10^{3} \mu \mathrm{m}^{2} \times \min ^{-1}$ (Fig. 4).
Comparison of bubble resolution in the different experimental groups-group A experiments

Table 1 lists the bubble shrinking rates after the isobaric breathing gas shift from air to heliox (80:20) in the four tissues as well as the rate measured in our previous control experiments with recompression to $285 \mathrm{kPa}$ breathing air throughout the observation period (Hyldegaard et al. 2001).

Two-way ANOVA testing using Bonferroni adjustment for multiple comparisons showed the independent variable of tissue to have a significant effect $(P=0.003)$ on the dependent variable, i.e. bubble shrinking rate. The effect is solely due to the slower bubble resolution in adipose tissue when compared with the other tissues that do not differ between each other. Post hoc comparisons showed only the adipose versus spinal white matter difference to be significant $(P<0.001)$. Breathing mixture, i.e. air or heliox (80:20), was also found to have a significant effect on bubble shrinking rate $(P=0.022)$ in favor of helium. The interaction between breathing mixture and tissue effects was not significant $(P=0.285)$.

Comparison of bubble resolution in the different treatment groups-group B experiments

Of the two heliox breathing mixtures, heliox (50:50) breathing with recompression to $405 \mathrm{kPa}$ was more effective than heliox (80:20) breathing at $285 \mathrm{kPa}(P<0.001)$ by means of one-way ANOVA testing.

\section{Discussion}

In our previous study (Hyldegaard et al. 2001) that followed the same basic experimental protocol as the current one, we found that all injected bubbles, irrespective of the tissue studied, shrank consistently during air breathing at $285 \mathrm{kPa}$ until they disappeared from view. This is to be expected because recompression will reverse the pressure gradients for gas exchange between bubble and tissue and form a gradient that forces gas into tissue. In the present study, we observed a transient marginal reduction in bubble shrinking rate or even a growth of air bubbles in adipose tissue, caused by the isobaric breathing gas shift from air to heliox (80:20), while at $285 \mathrm{kPa}$ pressure.

Although decompression induced spontaneous $\mathrm{N}_{2}$ bubbles in adipose tissue (Hyldegaard and Madsen 1989) or injected air bubbles in spinal white matter, skeletal muscle, or tendon (Hyldegaard and Madsen 1994; Hyldegaard et al. 1991) were observed to grow during breathing of air in normobaric conditions, indicating a continued tissue $\mathrm{N}_{2}$ super saturation, the present results may seem at variance with our previous observations (Hyldegaard and Madsen 
Fig. 3 Effect of immediate breathing gas shift from air to heliox (80:20) on air bubbles in spinal white matter. Breathing gas shift and recompression are initiated at the peak value of bubble growth caused by the decompression from 355 to $101.3 \mathrm{kPa}$, marked with vertical arrow. Each curve corresponds to a single bubble in one rat. Bubble shrinking rate was recalculated from $\mu \mathrm{m}^{2} \times \mathrm{min}^{-1}$ to $\mathrm{mm}^{2} \times \mathrm{min}^{-1}$
Fig. 4 Effect of immediate breathing gas shift from air to heliox (50:50) and recompression to $405 \mathrm{kPa}$ on air bubbles in spinal white matter. Breathing gas shift and recompression are initiated at the peak value of bubble growth cause by the decompression from 355 to $101.3 \mathrm{kPa}$, marked with arrow. Each curve corresponds to a single bubble in one rat. Bubble shrinking rate was recalculated from $\mu \mathrm{m}^{2} \times \min ^{-1}$ to $\mathrm{mm}^{2} \times \mathrm{min}^{-1}$
Immediate recompression to $285 \mathrm{kPa}$ on Heliox(80:20) breathing following air diving. Bubble size $\mathrm{mm}^{2} \quad$ Bubbles in spinal white matter.

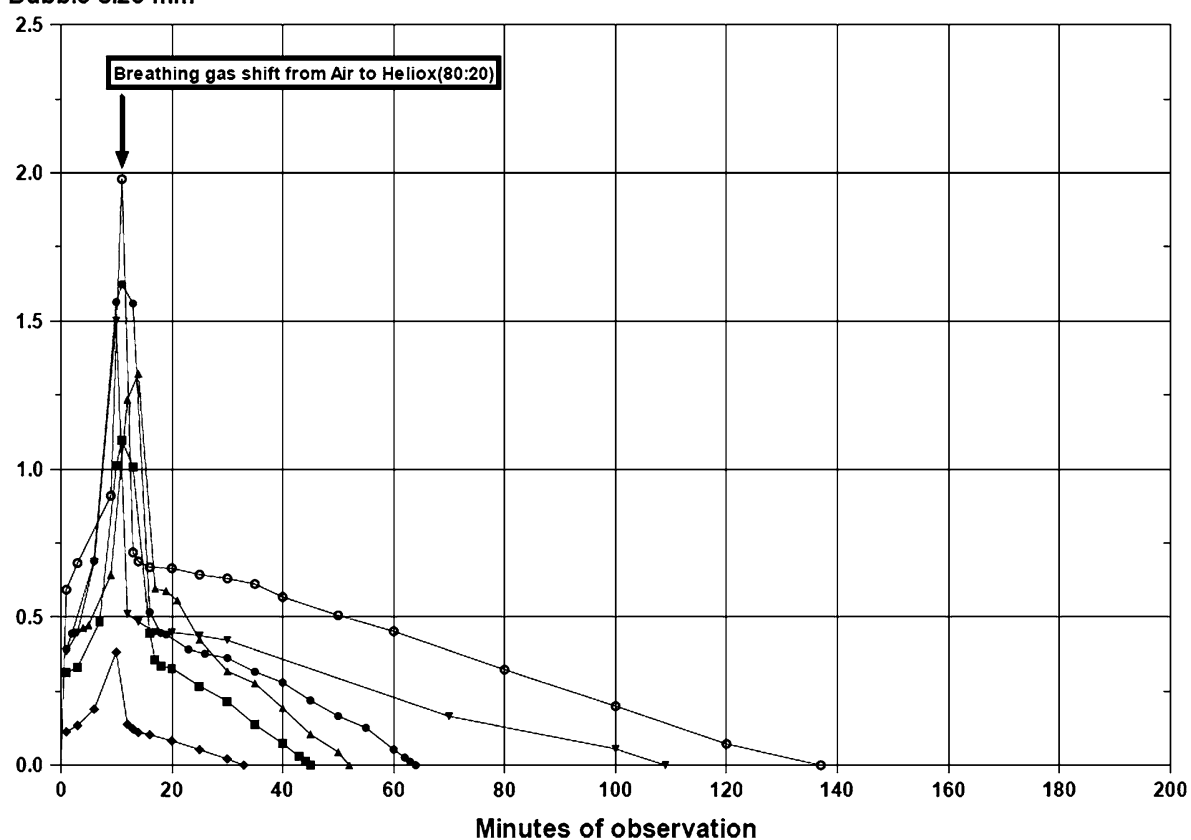

Immediate recompression to $405 \mathrm{kPa}$ on Heliox (50:50) breathing following air diving. Bubble size $\mathrm{mm}^{2} \quad$ Bubbles in spinal white matter.

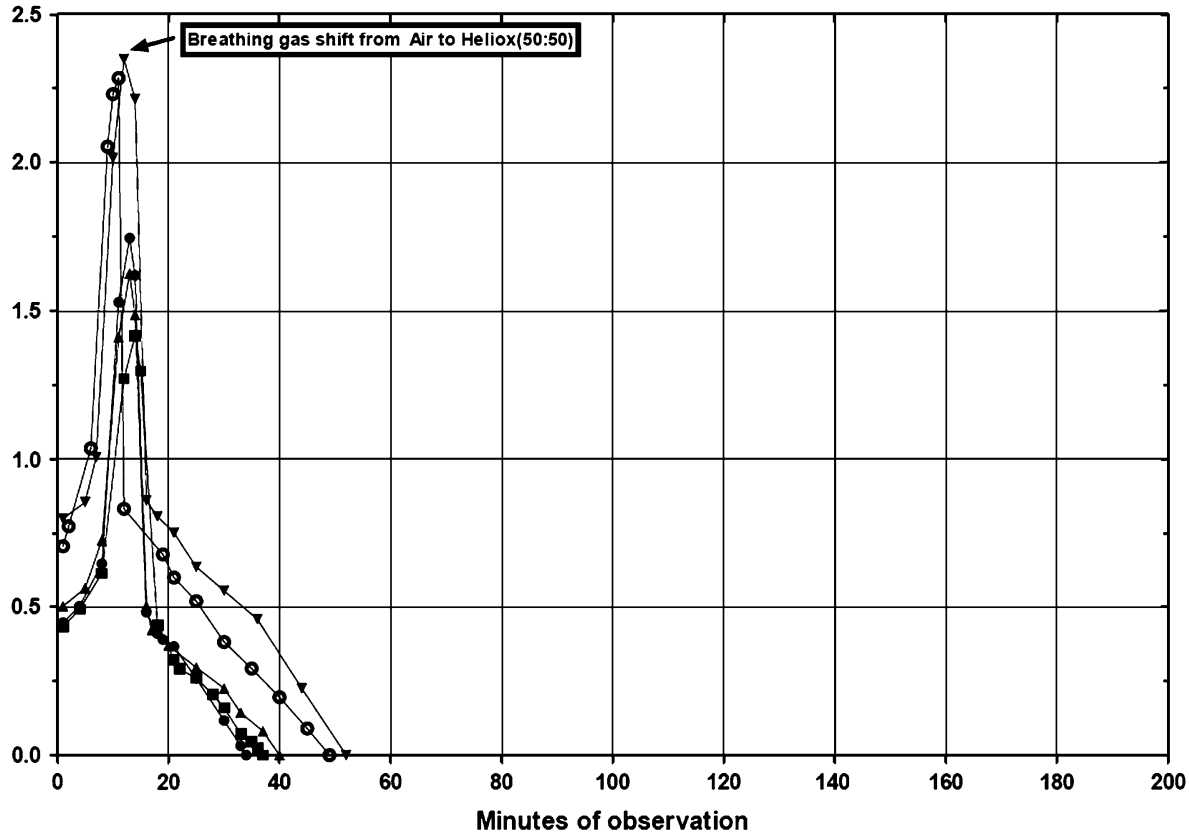

1989, 1994; Hyldegaard et al. 1991) of air bubbles in lipid and aqueous tissues immediately starting to shrink until disappearing during breathing of heliox (80:20). However, following a breathing gas shift, helium, and $\mathrm{N}_{2}$ will not only exchange between blood and bubble but also with the surrounding tissue. In adipose tissue, containing some $85 \%$ lipid material (Madsen et al. 1975) the average blood/tissue partition coefficient for $\mathrm{N}_{2}$ is 4.46 (Hyldegaard and Madsen 1989; Weathersby and Homer 1980) where as the corresponding value for helium is 1.70 . This 2.6 times greater tissue-blood partition coefficient for $\mathrm{N}_{2}$ relative to helium, causes adipose tissue to saturate (and desaturate) with helium more than twice as fast as with $\mathrm{N}_{2}$. Thus, upon an air to heliox breathing gas shift, a transient state of super 
saturation may be created, causing growth of $\mathrm{N}_{2}$ bubbles (D'Aoust and Lambertsen 1982; D'Aoust et al. 1977; Lambertsen and Idicula 1975). In aqueous tissues, this difference almost disappears, since the water/blood partition coefficient for $\mathrm{N}_{2}$ is 0.966 as compared to 1.043 for helium. Accordingly, if the rate of tissue saturation has any effect on bubble dynamics, one should expect this to be of importance in lipid as opposed to aqueous tissues, a fact corroborated by the results of the experiments presented here. D'Aoust BG and co-workers (1977) studied the continuous formation of intravascular gas bubble formation in goats, caused by an isobaric breathing gas shift from air to heliox breathing after a saturation exposure breathing 4.7 atmospheres $(476 \mathrm{kPa})$ of nitrogen $(0.3$ atmosphere of oxygen). However, no adverse effects-or the development of DCS were reported in these animals.

The failure to observe transient bubble growth or reduced rate of shrinkage during heliox (80:20) breathing at sea-level (i.e. normobaric conditions) on either DCS induced spontaneous $\mathrm{N}_{2}$ bubbles in adipose tissue (Hyldegaard and Madsen 1989) or injected air bubbles in spinal white matter, muscle, and tendon (Hyldegaard and Madsen 1994; Hyldegaard et al. 1991) suggests a quantitative effect since more gas (in mols) will be dissolved in the tissues during hyperbaric conditions and the growth/ slowing may be too subtle to be detected. However, since most bubbles shrank and disappeared during heliox breathing at a rate faster than during continued breathing of air, our results suggests that direct exchange of gas between bubble and blood rather than gas exchange with the surrounding tissue is the dominant determinant of bubble dynamics. In the case of perfusion limitation, bubbles should shrink after a breathing gas shift from air to heliox because of the lower solubility of helium in blood than that of $\mathrm{N}_{2}$ (Hills 1981; James 1981). As the $\mathrm{N}_{2}$ and helium saturation half-times $\left(T_{1 / 2}\right)$ in both spinal cord and muscle are four- to fivefold (Herspring et al. 2008; Madsen et al. 1975; Rubenstein and Arbit 1990) shorter than in adipose tissue, everything else being equal, one would expect a speeding up of the changes observed. Once $\mathrm{N}_{2}$ has disappeared in exchange for helium, less gas (in mols) will be present due to the lower blood- and tissue solubility of helium as compared to $\mathrm{N}_{2}$ and the bubbles will shrink. This situation will also apply to adipose tissue and tendon, but is reached much faster in the spinal cord and muscle.

In tendon, microinjected- as well as decompressioncreated bubbles will distribute along the streaks of the tendinous fibers (Hills and Butler 1978). Since the tendinous fibers surrounding the bubble are poorly perfused (Hills 1979) and thus presumably a slow tissue, a slower bubble shrinking rate when compared with muscle and spinal white matter should have been expected. If gas exchange in tendon were entirely dependent on extravascular diffusion, then helium breathing should cause bubble growth because the permeability of helium in an aqueous medium is greater for helium than for $\mathrm{N}_{2}$. However, the reduced perfusion may also increase diffusion from the bubble to these fibers, thus accelerating bubble disappearance. Further, the tendinous fibers are much more rigid structures, which may cause the tissue elastic forces to increase bubble pressure, forcing gas into the surrounding tissue. Shunting of gas by the counter current mechanism may be at work in the long stretch where arteries and veins lie in intimate contact in the tail (Homer et al. 1990; Hyldegaard and Madsen 1995) and the mechanism has been associated with the distribution of human limb pain DCS (Sowden et al. 1996). If counter current is at work, helium should be affected to a greater extent than $\mathrm{N}_{2}$ as long as the arterio-venous diffusion medium between the artery and vein is predominantly of aqueous nature, thus preventing helium from reaching the bubble and promote shrinkage.

In the clinical setting, the use of heliox breathing is combined with simultaneous recompression. The effect of recompression will be twofold; the first is the immediate reduction in bubble size according to Boyle's Law, secondly, recompression will reverse the inwards diffusion from tissue to bubble of $\mathrm{N}_{2}$ by an immediate increase of the $\mathrm{N}_{2}$ partial pressure in the bubble. As outlined above, the observed bubble growth caused by heliox (80:20) breathing is marginal, with very little effect on bubble radius. This potentially adverse, but transient effect is unlikely to have any clinical implications as bubble radius is hardly changed and the overall speed of bubble resolution is greater during heliox (80:20) breathing when compared with continuous air breathing. Further, the injected bubbles studied in these experiments are several magnitudes larger than bubbles separated in tissues after decompression (Francis et al. 1990; Hyldegaard and Madsen 1989). Accordingly, when air diving induced DCS is treated with recompression and heliox breathing, transient bubble growth will be even less likely. A contributing cause for the disappearance of $\mathrm{N}_{2}$ bubbles during heliox breathing after recompression could be that once the bubbles have become smaller, surface tension will increase the pressure inside the bubble sufficient to overcome the pressure gradients driving gas (i.e. helium) into the bubble.

The group B experiments were performed in order to test whether an immediate breathing gas shift from air to heliox (80:20) or (50:50) with subsequent recompression (imitating actual treatment profiles), would cause transient bubble growth or reduced rate of bubble disappearance in spinal white matter, thus causing potential deterioration of neurological DCS symptoms. This did not happen. On the contrary, an immediate breathing gas shift from air to heliox $(80: 20)$ or $(50: 50)$ combined with recompression 
caused bubbles to shrink consistently until they disappeared from view (Figs. 3, 4). If the bubble shrinking rate in the present $\mathrm{B}$ experiments are compared to the previously reported experiments, performed with the same protocol and applying recompression breathing air throughout (Hyldegaard et al. 2001), the rate at both heliox (80:20) and (50:50) breathing comes out significantly faster $(P<0.01$ and $P<0.001$, respectively, one-way ANOVA and Bonferroni correction for multiple analysis among groups; Altman 1991). Further, in our previous experiments (Hyldegaard et al. 2001), the recompression during air breathing was initiated with a certain time delay, which would allow some tissue desaturation. Thus, one would expect that prompt recompression breathing air-everything else being equal-would accentuate the bubble resolution difference between the air breathing controls and heliox breathing experiments because of the higher $\mathrm{N}_{2}$ tissue partial pressure. It could be argued that the time delay from decompression to bubble injection and recompression in our previous report (Hyldegaard et al. 2001) had allowed for local bubble/tissue biochemical reactions, making the gas exchange surface between bubble and tissue less permeable. This introduced a diffusion barrier that does not exist if recompression is initiated immediately after decompression. Whereas the concept of a biochemical bubble diffusion barrier remains unproven, it is an undisputed fact that the tissue $\mathrm{N}_{2}$ partial pressure is greater immediately after decompression when compared with any later stage.

Whereas the beneficial effect of heliox breathing in the treatment of air-diving-induced DCS can be explained by an increased bubble disappearance rate as outlined above, DCS is also known to be associated with intravascular bubble formation causing disruption of endothelial integrity, disruption of the blood-brain barrier as well as activation of leukocytes with cerebral blood-flow reduction, ischemia and infarction (Francis and Micthell 2003). Recent experiments have demonstrated that the noble gas helium possesses important cellular protective effects in the organism (Oei Gezina et al. 2010), and has been shown to reduce infarct volume in an animal model of focal cerebral ischemia-reperfusion injury (David et al. 2009; Pan et al. 2007) and to ameliorate cellular damage in an in vitro model of traumatic brain injury (Coburn et al. 2008). It is conceivable that these neuroprotective effects of helium may be of equal importance in the treatment of neurological DCS.

In conclusion, recompression breathing heliox mixtures, whether administered prior to recompression or during the stay at pressure, caused an increased rate of air bubble disappearance. In previous experiments (Hyldegaard and Madsen 1989, 1994; Hyldegaard et al. 1991, 2001), the inert breathing gas switch from $\mathrm{N}_{2}$ to helium, or the recompression were done with a certain time delay after the hyperbaric air diving exposure. Accordingly, it could be argued that a sufficiently large amount of $\mathrm{N}_{2}$ had desaturated from the tissue, so a possible bubble growth caused by the subsequent faster rate of helium tissue saturation went undetected. If this were the case, then treatments involving heliox breathing after air diving, would seem the better choice in DCS cases with delayed recompression because of the reduced tissue $\mathrm{N}_{2}$ partial pressure. However, since the effect of recompression breathing heliox mixtures in the group B experiments were also one of consistent bubble shrinkage, the observation does not support the hypothesis that heliox breathing should be more effective in cases of delayed treatments as opposed to cases with immediate heliox recompression of air-dive DCS, nor that deep tissue isobaric counter diffusion will cause air bubbles to grow or will prolong their resolution when heliox breathing is combined with recompression. Therefore, in line with previous clinical experience (Aharon-Peretz et al. 1993; Barnard and Elliott 1966; Bennett et al. 2007; Douglas and Robinson 1988; Drewry and Gormann 1993; Gorman 1996; Imbert 1996; Kol and Melamed 1993; Shupak et al. 1997), we see no reason for reservations in the use of heliox breathing at any stage during recompression treatment for air diving induced DCS and would recommend such use whenever available.

Acknowledgments The technical assistance of Senior Technician Israel Shreger is gratefully acknowledged. This work would have been impossible without it. The present work was supported by The Danish Council for Independent Research Medical Sciences (Grants no. 12-9160, 12-0336-1, and 12-1073-1), The A.P. Møller Foundation for the Advancement of Medical Science, The Laerdal Foundation for Acute Medicine, AGA AB Medical Research Fund, Idrættens Forskningsråd and The Lundbeck Research Foundation.

Open Access This article is distributed under the terms of the Creative Commons Attribution Noncommercial License which permits any noncommercial use, distribution, and reproduction in any medium, provided the original author(s) and source are credited.

\section{References}

Aharon-Peretz J, Adir Y, Gordon CR, Kol S, Gal N, Melamed Y (1993) Spinal cord decompression sickness in sport diving. Arch Neurol 50:753-756

Altman DG (1991) Practical statistics for medical research. Chapman \& Hall, London

Barnard EEP, Elliott DH (1966) Decompression sickness: paradoxial response to recompression therapy. Br Med J 2:809-810

Bennett MH, Lehm JP, Mitchell SJ, Wasiak J (2007) Recompression and adjunctive therapy for decompression illness. Cochrane Database Syst Rev 18(2):CD005277

Coburn M, Maze M, Franks NP (2008) The neuroprotective effects of xenon and helium in an in vitro model of traumatic brain injury. Crit Care Med 36:588-595

D'Aoust BG, Lambertsen CJ (1982) Isobaric gas exchange and supersaturation by counterdiffusion. In: Bennett PB, Elliott DH 
(eds) The physiology and medicine of diving. Best Publishing Company, San Pedro, pp 383-403

D'Aoust BG, Smith KH, Swanson HT, White R (1977) Venous gas bubbles: production by transient, deep isobaric counterdiffusion of helium against nitrogen. Science 197:889-891

David HN, Haelewyn B, Chazalviel L, Lecocq M, Degoulet M, Risso JJ, Abraini JH (2009) Post-ischemic helium provides neuroprotection in rats subjected to middle cerebral artery occlusioninduced ischemia by producing hypothermia. J Cereb Blood Flow Metab 29:1159-1165

Douglas JDM, Robinson C (1988) Heliox treatment for spinal decompression sickness following air dives. Undersea Biomed Res 15:315-319

Drewry A, Gormann DF (1993) A preliminary report on a prospective randomised double-blind controlled study of oxygen and oxygen-helium in the treatment of air-diving decompression illness. Undersea Hyperb Med 20(Suppl): 19

Francis TJR, Micthell SJ (2003) Pathophysiology of decompression sickness. In: Brubakk AO, Neuman T (eds) Bennett and Elliott's physiology and medicine of diving. Saunders, London, pp 530-557

Francis TJR, Griffin JL, Homer LD, Pezeshkpour GH, Dutka AJ, Flynn ET (1990) Bubble-induced dysfunction in acute spinal cord decompression sickness. J Appl Physiol 68:1368-1375

Gorman DF (1996) Treatment of arterial gas embolism. In: Moon RE, Sheffield PJ (ed) Treatment of decompression illness. 45th workshop of the Undersea and Hyperbaric Medical Society, FL, USA, pp 96-100

GraphPad (2003) Instat version 3.06 for Windows, San Diego, CA, USA

GraphPad (2009) Prism version 5.03 for Windows, San Diego, CA, USA

Hedenqvist P, Hellebrekers LJ (2003) Laboratory animal analgesia, anesthesia, and euthanasia. In: Hau J, Van Hoosier GL Jr (eds) Handbook of laboratory animal science. CRC Press LLC, Boca Raton, pp 413-455

Herspring KF, Ferreira LF, Copp SW, Snyder BS, Poole DC, Musch TI (2008) Effects of antioxidants on contracting spinotrapezius muscle microvascular oxygenation and blood flow in aged rats. J Appl Physiol 105:1889-1896

Hills BA (1979) Intermittent flow in tendon capillary bundles. J Appl Physiol 46(4):696-702

Hills BA (1981) Scientific considerations in recompression therapy. In: James PB, McCallum RI, Rawlins JSP (eds) Proceedings of VIIth European Undersea Biomedical Society Congress. Report of proceedings of a symposium on decompression sickness, Cambridge, pp 143-162

Hills BA, Butler BD (1978) The kangaroo rat as a model for type 1 decompression sickness. Undersea Biomed Res 5(4):309-321

Homer LD, Weathersby PK, Survanshi S (1990) How countercurrent blood flow and uneven perfusion affect the motion of inert gas. J Appl Physiol 69(1):162-170

Hyldegaard O, Jensen T (2007) Effect of heliox, oxygen and air breathing on helium bubbles after heliox diving. Undersea Hyperb Med 34(2):107-122

Hyldegaard O, Madsen J (1989) Influence of heliox, oxygen, and $\mathrm{N}_{2} \mathrm{O}-\mathrm{O}_{2}$ breathing on $\mathrm{N}_{2}$ bubbles in adipose tissue. Undersea Biomed Res 16:185-193

Hyldegaard O, Madsen J (1994) Effect of air, heliox, and oxygen breathing on air bubbles in aqueous tissues in the rat. Undersea Hyperb Med 21:413-424

Hyldegaard O, Madsen J (1995) Effect of $\mathrm{SF}_{6}-\mathrm{O}_{2}(80 / 20)$ breathing on air bubbles in rat tissues. Undersea Hyperb Med 22(4):355-365

Hyldegaard O, Moller M, Madsen J (1991) Effect of $\mathrm{He}-\mathrm{O}_{2}, \mathrm{O}_{2}$, and $\mathrm{N}_{2} \mathrm{O}-\mathrm{O}_{2}$ breathing on injected bubbles in spinal white matter. Undersea Biomed Res 18:361-371
Hyldegaard O, Kerem D, Melamed Y (2001) Effect of combined recompression and air, oxygen, or heliox breathing on air bubbles in rat tissues. J Appl Physiol 90:1639-1647

Imbert JP (1996) Evolution and performances of Comex treatment tables. In: Moon RE, Sheffield PJ (ed) Treatment of decompression illness. 45th workshop of the Undersea and Hyperbaric Medical Society, FL, USA, pp 389-394

James PB (1981) Problem areas in the therapy of neurological decompression sickness. In: James PB, McCallum RI, Rawlins JSP (eds) Proceedings of VIIth European Undersea Biomedical Society Congress. Report of proceedings of a symposium on decompression sickness, Cambridge, pp 127-142

James PB, Imbert JP, Arnoux GA (1986) The Comex medical book. Companie Maritime d'Expertises, Marseille

Kol S, Melamed Y (1993) Oxy-helium treatment for spinal decompression sickness following air dives. Undersea Hyperb Med 20:147-154

Lambertsen CJ, Idicula J (1975) A new gas lesion syndrome in man induced by "isobaric counterdiffusion". J Appl Physiol 39:434-443

Lang $\varnothing$ T, Mørland T, Brubakk AO (1996) Diffusion coefficients and solubility coefficients for gases in biological fluids and tissues: a review. Undersea Hyperb Med 23(4):247-272

Madsen J, Malchow-Møller A, Waldorff S (1975) Continous estimation of adipose tissue blood flow in rats by $133-\mathrm{Xe}$ elimination. J ApplPhysiol 39:851-856

Moon RE, Sheffield PJ (1995) Treatment of decompression illness. 45th workshop of the Undersea and Hyperbaric Medical Society, Palm Beach, FL

Oei Gezina TML, Weber NC, Hollmann MW, Preckel B (2010) Cellular effects of helium in different organs. Anesthesiology 112:1503-1510

Pan Y, Zhang H, VanDeripe DR, Cruz-Flores S, Panneton WM (2007) Heliox and oxygen reduce infarct volume in rat model of focal ischemia. Exp Neurol 205:587-590

Rasband W (1996). Image. Image processing and analysis. Version 1.61. National Institutes of Health Research Services Branch. http://rsb.info.nih.gov/nih-image/download

Roughan JV, Ojeda OB, Flecknell PA (1999) The influence of preanaesthetic administration of buprenorphine on the anaesthetic effects of ketamine/medetomidine and pentobarbitone in rats and the consequence of repeated anaesthesia. Lab Anim 33:234-242

Rubenstein A, Arbit E (1990) Spinal cord blood flow in the rat under normal physiological conditions. Neurosurgery 27:882-886

Sejrsen P (1985) Shunting by diffusion of gas in skeletal muscle and brain. In: Johansen K, Burggren WW (eds) Cardiovascular shunts, Alfred Benzon Symposium, 21, Munksgaard, Copenhagen, pp 452-466

Sejrsen P, Tønnesen KH (1972) Shunting by diffusion of inert gasses in skeletal muscle. Acta Physiol Scand 86:82-91

Shupak A, Melamed Y, Ramon Y, Bentur Y, Abramovich A, Kol S (1997) Helium and oxygen treatment of severe, air-divinginduced neurological decompression sickness. Arch Neurol 54:305-311

Sowden LM, Kindwall EP, Francis TJ (1996) The distribution of limp pain in decompression sickness. Aviat Space Environ Med 67:74-80

SPSS Inc. (1998) Statistical package of the social sciences. Chicago, IL

Torbati D, Ramirez J, Han E, Camacho MT, Sussmane JB, Raszynski A, Wolfsdorf J (1999) Experimental critical care in rats: gender differences in anesthesia, ventilation, and gas exchange. Crit Care Med 27:1878-1884

Weathersby PK, Homer LD (1980) Solubility of inert gases in biological fluids and tissues: a review. Undersea Biomed Res 7:277-296

Zambricki EA, D'Alecy LG (2004) Rat sex differences in anesthesia. Comp Med 54:49-53 